\title{
DESIGN OF TRI BANDS ELLIPTICAL MICROSTRIP ANTENNA FOR SATELLITE COMMUNICATION
}

\author{
Dr. Raad H. Thaher ${ }^{1}$
}

${ }^{*}$ Hasanain M. jassim²

1) Prof. Dr., Electrical Engineering Dep., Al-Mustansiriyah University College of Engineering، Baghdad, Iraq.

2) MSc. Student, Electrical Engineering Dep., Al-Mustansiriyah University College of Engineering, Baghdad, Iraq.

\begin{abstract}
A microstrip antenna with a triple band elliptical patch has been designed. The antenna has dimensions of

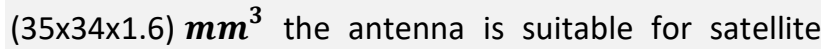
applications and is mounted on a substratum with a relative dielectric constant $\left(\boldsymbol{\varepsilon}_{r}\right)$ of 4.3 and loss tangent (tan $\delta)$ of 0.025. The antenna covers a frequency of (6.1-6.3) $\mathrm{GHz},(7.4-7.8) \mathrm{GHz}$ and $(8-8.4) \mathrm{GHz}$ and with a reflection coefficient (S11) of (-37.78), (-35.646), and (-41.8) respectively. The antenna gain ranges from $1.2 \mathrm{dBi}$ to 2.59 $\mathrm{dBi}$ and standing voltage wave (VSWR) less than 2 . The antenna has been adjusted by inserting steps in the feed line and slots to the patch to improve impedance matching and group delay characteristics. CST software used to obtain the simulation results.
\end{abstract}

Keywords: Microstrip elliptical antenna, UWB, satellite applications, triple-band.

\section{Introduction}

Antenna became an essential part in the field of wireless communication since 1888. The modern wireless communication system demands low profile, lightweight, high gain, and highefficiency characteristics for an application like satellite, radar, mobile, etc.[1]. The microstrip antenna attracts more attention because of its features such as low profile, low cost, lightweight, easy fabrication and compatibility to the printed circuit board[2]. Despite its features, there are also some drawbacks like narrow bandwidth, low gain and surface wave excitation[3,4]. In 2002, the Federal Communication Commission (FCC) approved for mercantile purposes an ultra-wideband (UWB) at the frequency of (3.1-10.6) GHz. The UWB technology attracts attention because of the need to provide more information with a high data transmission rate for more users, and it has features such as high data in short-range, high multipath immunity, low power consumption, low cost, spectrum reuse and simple hardware architecture[5,6,7]. However, it interferes with the narrowband communication system in the frequency range (3.4-3.69) $\mathrm{GHz}$ and (5.15-5.825) $\mathrm{GHz}$, to solve this problem a lot of researches for band notch were done[8,9,10]. The UWB antenna is the core element of the UWB system and should have features such as greater impedance bandwidth, stable radiation behavior, stable gain and operating efficiency[11,12]. Many microstrip antenna designed for UWB application like in (2020) Abhishek Patel and Manoj Singh Parihar designed a triple band notch

*CorrespondingAuthor:hasaneenmaytham1995@gmail.com 
microstrip antenna. The antenna patch contains a rectangular shaped patch covering the frequency spectrum from $3.1 \mathrm{GHz}$ to $10.6 \mathrm{GHz}$ with a partial ground and an E-shaped resonator[13]. In (2018) Jeet Banerjee, et al. designed a compact printed triple band-notched UWB antenna with a partial ground the antenna has a band notch in frequency ranges (3.3-3.8) GHz, (5.15-5.85) GHz and (7.98.4) GHz[14]. In (2018) Sweta Agrawal, et al. They designed a compact circular microstrip patch antenna with a partial ground structure for ultra-wide band application, the antenna is loaded with a C-shaped slot in the patch and Sshaped slot in the microstrip feed line. The Cshaped and S-shaped slots have been used to create band-notched characteristics for the band (3.30-3.60) GHz and band (5.10-5.80) GHz. The frequency band $(7.25-7.75) \mathrm{GHz}$ is notched using Split Ring Resonator as an electromagnetic coupling element near the feed line which creates band stop properties[15]. In (2017) Sayed Arif Ali, et al. They designed a microstrip antenna with Hexagonal Flower-shaped Patch and partial ground structure for the ultra-wide band application. The antenna consists of two C-shape slot resonators in the patch and two parasitic strips parallel to the microstrip feed line. The antenna has three-band notch characteristics in the bands (3.3-4.2) GHz, (5.15-5.825) GHz, and (8.025-8.4) GHz[16]. In this research, an elliptical triple-band antenna has been designed for satellite applications. The antenna operates at frequencies of (6.1-6.3) GHz, (7.4-7.8) GHz and (8-8.4) GHz, with a reflection coefficient (S11) of (-37.78), (-35.646) and (-41.8) respectively. The antenna is adjusted to get a better match impedance and group delay characteristics by inserting steps in the feed line and slots in the patch. The required design equations are outlined below [3]:

$\varepsilon_{e f f}=\frac{\varepsilon_{r}+1}{2}+\frac{\varepsilon_{r}-1}{2}\left[1+12 \frac{h}{w}\right]^{-1 / 2}$
Where $\varepsilon_{\text {eff }}$ is effective dielectric constant, $\boldsymbol{\varepsilon}_{\boldsymbol{r}}$ is the relative dialectical constant, $w$ is the width of the patch (Semi-major axis), and $h$ is the thickness of the substrate.

$L_{g}=L+6 h$

Where $L_{g}$ the length of the ground and $\mathrm{L}$ is the length of the patch (semi-minor axis).

$W_{g}=w+6 h$

Where $W_{g}$ is the ground width.

$\lambda=c / f$

Where $\lambda$ the Wavelength, $\mathrm{f}$ is the frequency and c speed of light in vacuum.

$\lambda_{g}=\lambda / \sqrt{\varepsilon_{e f f}}$

$L_{f}=\lambda_{g} /_{4}$

Where $L_{f}$ is the length of the feed line.

\section{The proposed antenna}

The designed antenna is shown in Fig 1. The antenna substance is built by using FR-4 with a relative dielectric constant $\left(\boldsymbol{\varepsilon}_{\boldsymbol{r}}\right)$ of $4.3, \mathrm{~h}=1.6$ $\mathrm{mm}$, and 0.025 loss tangent. The patch and the ground are built by using annealed copper with thickness $\mathrm{t}=0.035 \mathrm{~mm}$. Table 1 shows the best values we obtained for the antenna parameter through a parametric study. CST software has been utilized to obtain the simulation results.
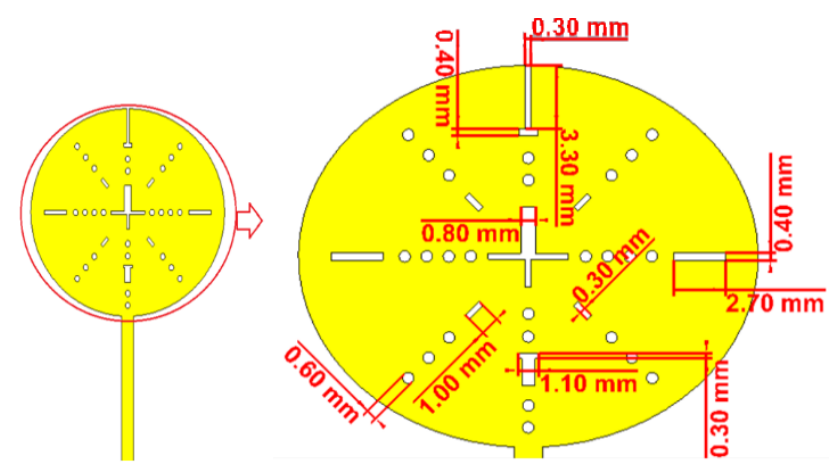

(a) 


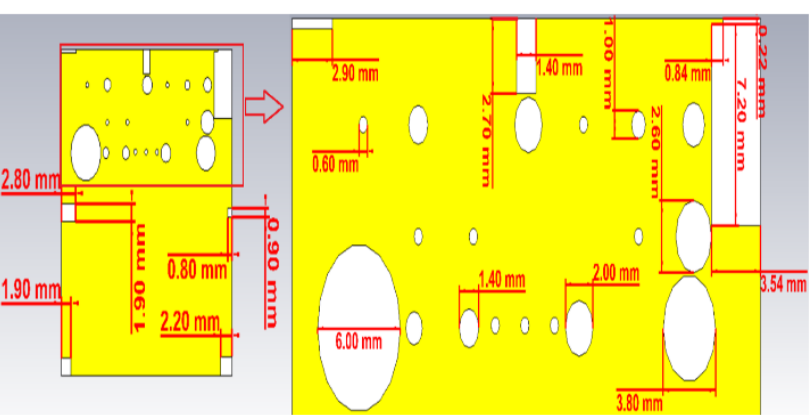

(b)

Figure 1. The designed antenna (a) anterior view (b) posterior view

Table 1. The best values for antenna parameters

\begin{tabular}{cccc}
\hline parameter & Value & parameter & value \\
$\mathrm{h}$ & $1.6 \mathrm{~mm}$ & substrate width & $34 \mathrm{~mm}$ \\
$\mathrm{t}$ & $\begin{array}{c}0.035 \mathrm{~m} \\
\mathrm{~m}\end{array}$ & Semi-major axis & $12 \mathrm{~mm}$ \\
& $15 \mathrm{~mm}$ & semi-minor axis & $10 \mathrm{~mm}$ \\
$\mathrm{~L}_{\mathrm{f}}$ & $1.45 \mathrm{~mm}$ & Substrate length & $35 \mathrm{~mm}$ \\
$\mathrm{~W}_{\mathrm{f}}$ & $35 \mathrm{~mm}$ & $\mathrm{~W}_{\mathrm{g}}$ & $34 \mathrm{~mm}$ \\
$\mathrm{~L}_{\mathrm{g}}$ & & &
\end{tabular}

The variation of $S 11$ with different frequencies is demonstrated in Fig. 2, where

$S 11=10 \log \Gamma$

$\Gamma=\frac{Z_{R}-Z_{o}}{Z_{R}+Z_{o}}$

Where $\Gamma$ is the reflection coefficient, $Z_{R}$ is the load impedance and $Z_{o}$ is the Characteristic impedance[1].

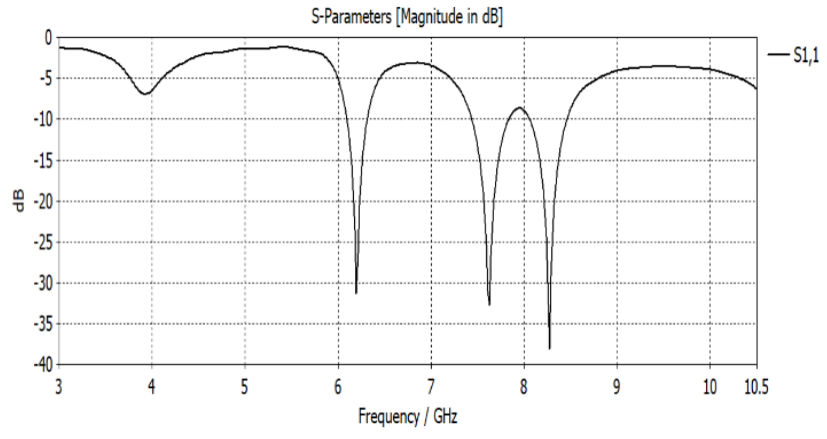

Figure 2. S11 Variation with frequency
One of the essential parameters for the UWB antenna is the group delay. The antenna should be able to transmit the signal with minimal distortion (i.e., small group delay) [1,3]. Fig. 3 shows the group delay of the designed antenna as the group delay ranges from $-12.6 \mathrm{~ns}$ to $12.8 \mathrm{~ns}$. Hence, it will be modified, as shown in the next section.

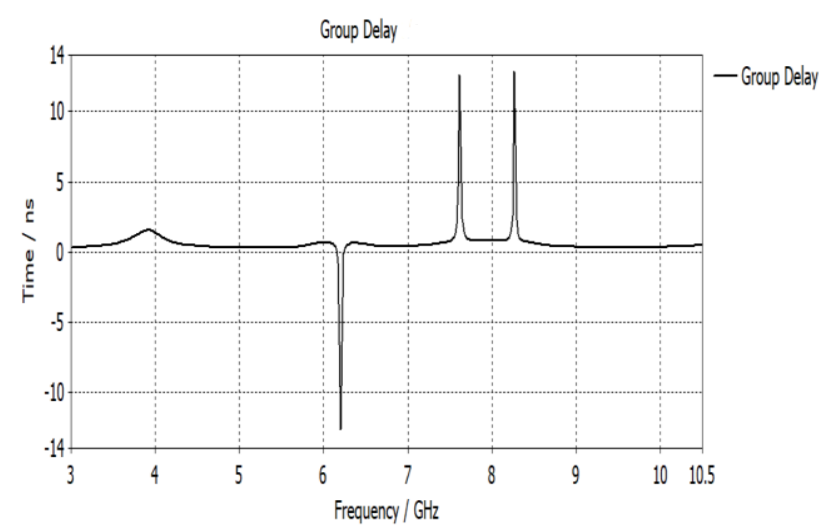

Figure 3. The group delay of the designed antenna

\section{The modified antenna}

Because of the high distortion of the designed antenna, steps added in the feed line and slots to the patch so that the designed antenna will have better impedance matching characteristics and less distortion (i.e. group delay from $-1.08 \mathrm{~ns}$ to $2.75 \mathrm{~ns})$, Fig. 4 demonstrated the adjusted antenna.
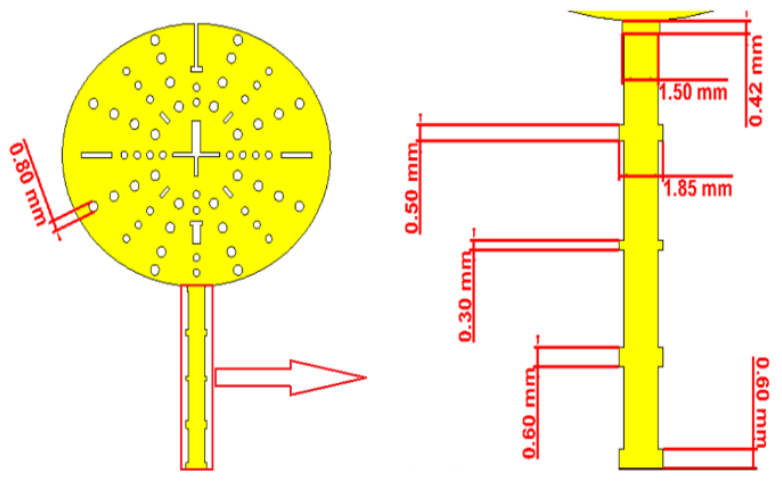

(a)

(b) 


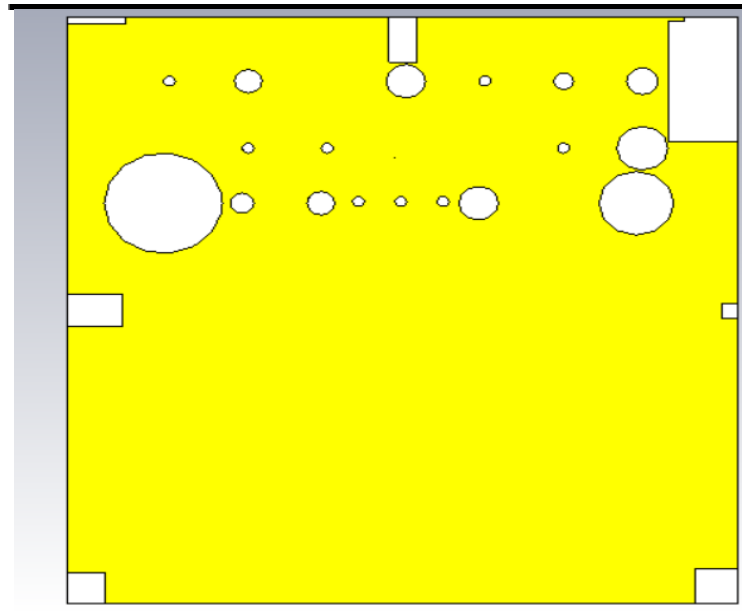

Figure 4. The adjusted antenna (a) front view (b) rear view

The $\mathrm{S} 11$ change with the frequencies is shown in Fig. 5, the antenna occupies a bandwidth of (6.16.3) $\mathrm{GHz},(7.4-7.8) \mathrm{GHz}$ and with a reflective coefficient (S11) of (8-8.4) GHz and (-37.78), ($35.646)$ and $(-41.8)$ respectively.

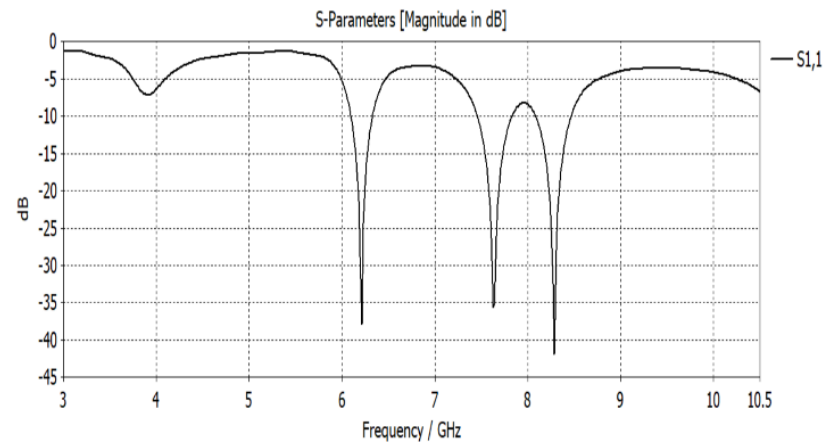

Figure 5. $S 11$ Vs. the frequency for the adjusted antenna

The distortion of the modified antenna is less than that of the proposed antenna (i.e. group delay from $-1.08 \mathrm{~ns}$ to $2.75 \mathrm{~ns}$ ) as shown in Fig. 6.

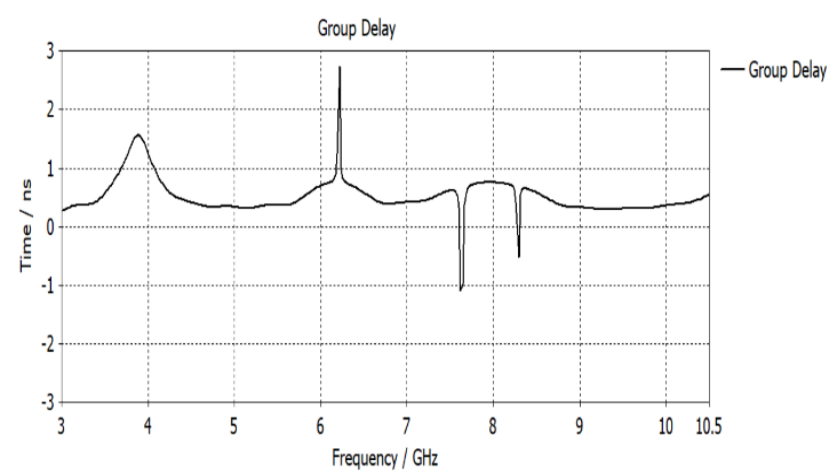

Figure 6. The group delay of the adjusted antenna
The gain of the modified antenna demonstrated in Fig. 7, the gain of the modified antenna varies from $1.2 \mathrm{dBi}$ to $2.59 \mathrm{dBi}$.

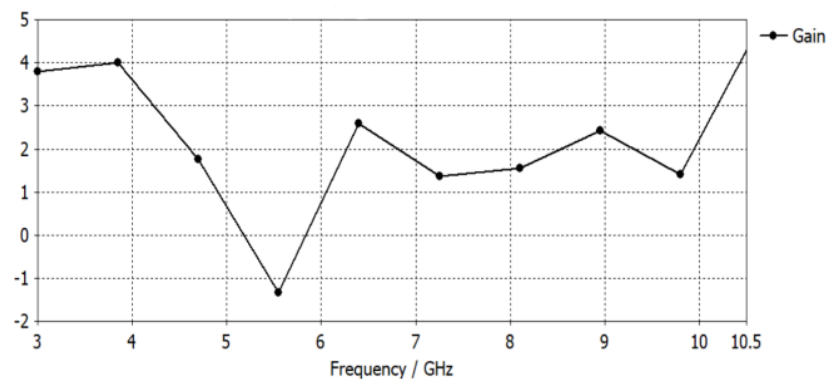

Figure 7. Gain Vs. the frequency for the modified antenna

The modified antenna surface current distribution at frequencies $6.213 \mathrm{GHz}, 7.624$ $\mathrm{GHz}$, and $8.287 \mathrm{GHz}$ demonstrated in Fig. 8, with a maximum current of $110 \mathrm{~A} / \mathrm{m}, 121 \mathrm{~A} / \mathrm{m}$ and $123 \mathrm{~A} / \mathrm{m}$ respectively.
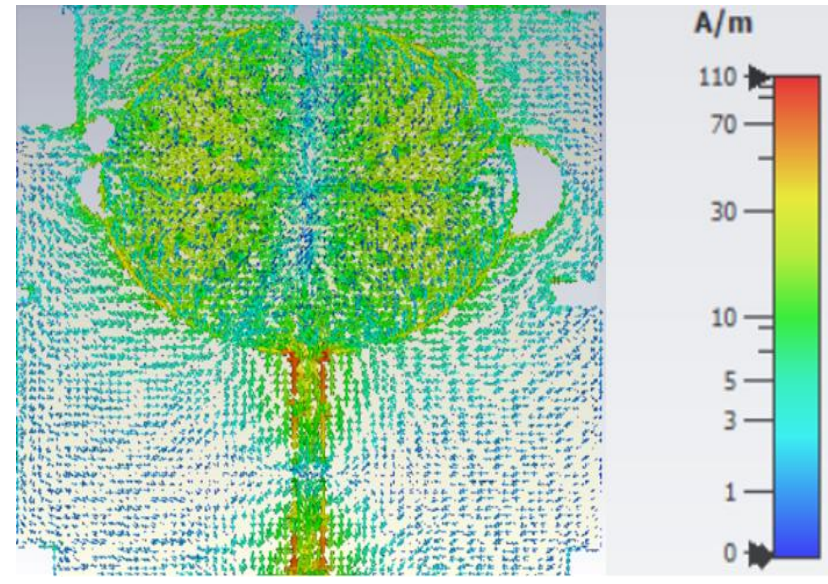

(a)

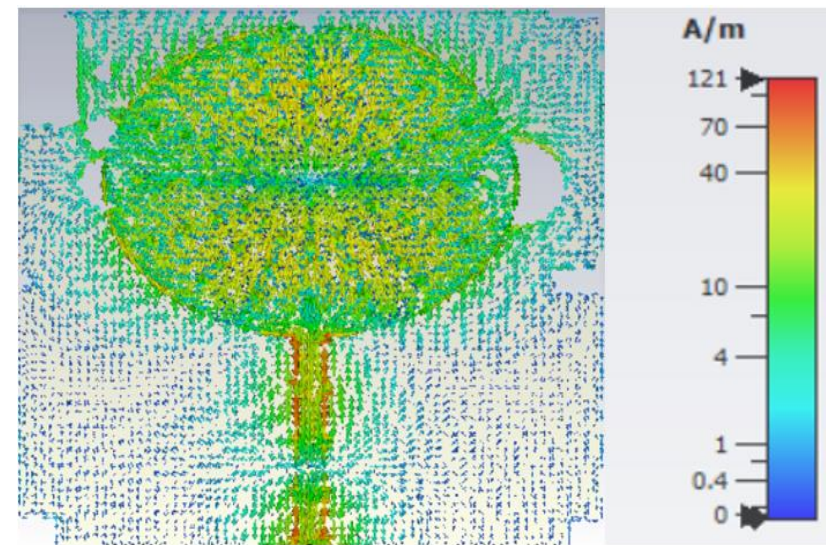

(b) 


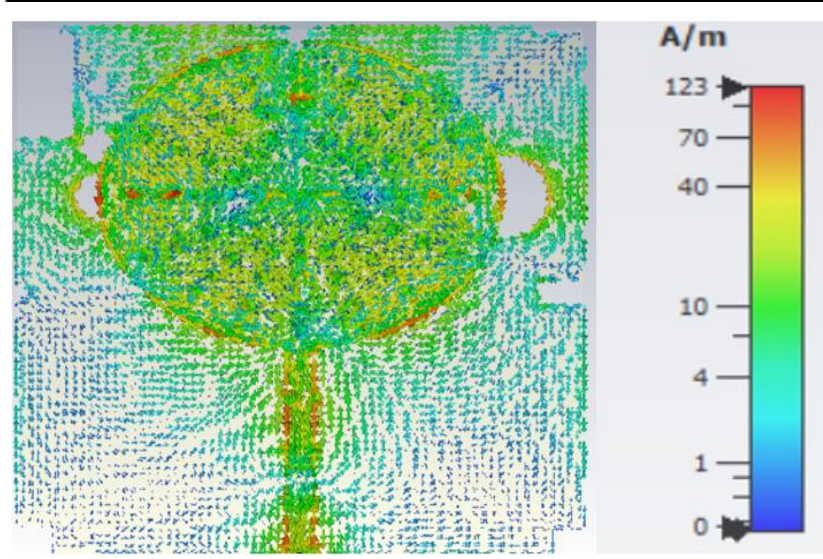

(c)

Figure 8. The surface current allocation of the adjusted antenna for (a) $\mathrm{f}=6.213 \mathrm{GHz}$ (b) $\mathrm{f}=7.624 \mathrm{GHz}$ (c) $\mathrm{f}=$ $8.287 \mathrm{GHz}$

The far-field (H-field and E-field) pattern or also known as antenna pattern, Fig. 9 shown the farfield of the adjusted antenna at frequencies 6.213 $\mathrm{GHz}, 7.624 \mathrm{GHz}$, and 8.287 GHz.

Farfield Directivity Abs (Phi=90)

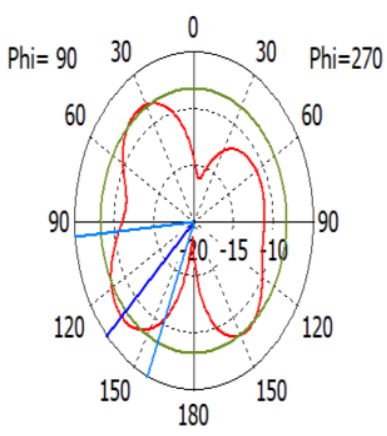

Theta / deg vs. dBi

(a)

Farfield Directivity Abs (Theta $=90$ )

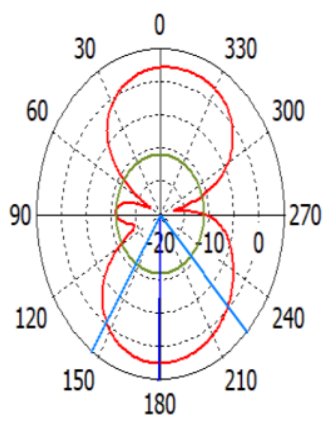

Phi / deg vs. dBi
— farfield $(f=6.213)$

Frequency $=6.213 \mathrm{GHz}$

Main lobe magnitude $=-7.63 \mathrm{dBi}$ Main lobe direction $=133.0$ deg. Angular width $(3 \mathrm{~dB})=61.7 \mathrm{deg}$. Side lobe level $=-0.6 \mathrm{~dB}$

— farfield $(f=6.213)$

Frequency $=6.213 \mathrm{GHz}$ Main lobe magnitude $=2.44 \mathrm{dBi}$ Main lobe direction $=179.0 \mathrm{deg}$. Angular width $(3 \mathrm{~dB})=78.1 \mathrm{deg}$. Side lobe level $=-13.5 \mathrm{~dB}$

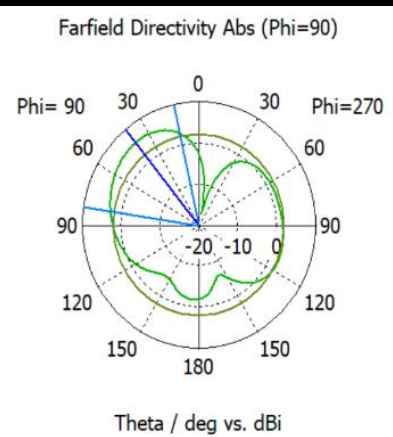

(c)

Farfield Directivity Abs (Theta $=90$ )

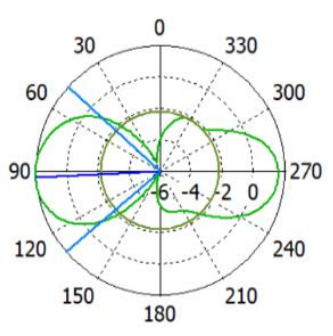

Phi / deg vs. dBi

(d)

Farfield Directivity Abs (Phi=90)

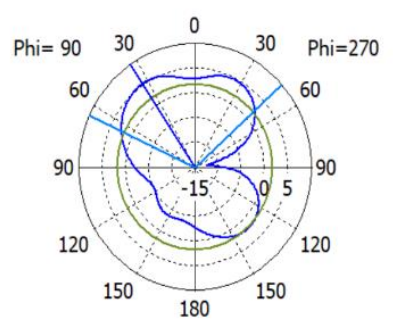

Theta / deg vs. $\mathrm{dBi}$

(e)

Farfield Directivity Abs (Theta $=90$ )

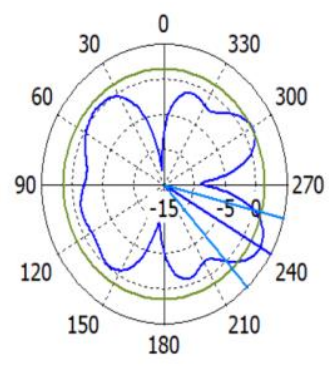

Phi / deg vs. dBi

(f)

Figure 9. Far-field of the adjusted antenna (a) E-field in $6.213 \mathrm{GHz}$ (b) $\mathrm{H}$-field in $6.213 \mathrm{GHz}$ (c) E-field in 7.624 $\mathrm{GHz}$ (d) H-field in $7.624 \mathrm{GHz}$ (e) E-field in $8.287 \mathrm{GHz}(\mathrm{f})$ $\mathrm{H}$-field in $8.287 \mathrm{GHz}$

The 3D radiation pattern of the modified antenna at frequencies $6.213 \mathrm{GHz} 7.624 \mathrm{GHz}$ and 8.287 
$\mathrm{GHz}$ and with maximum directivity of $6.13 \mathrm{dBi}$, $5.8 \mathrm{dBi}$, and $5.44 \mathrm{dBi}$ respectively is demonstrated in Fig. 10.
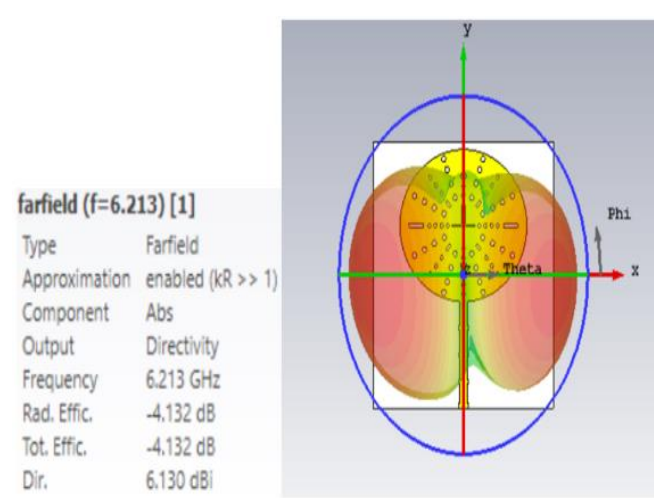

(a)
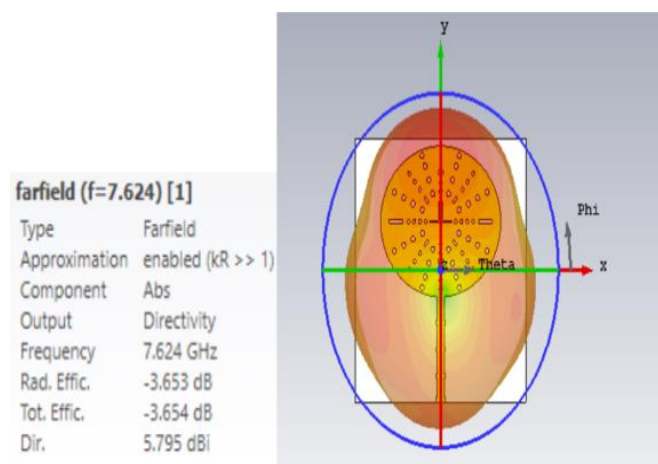

(b)

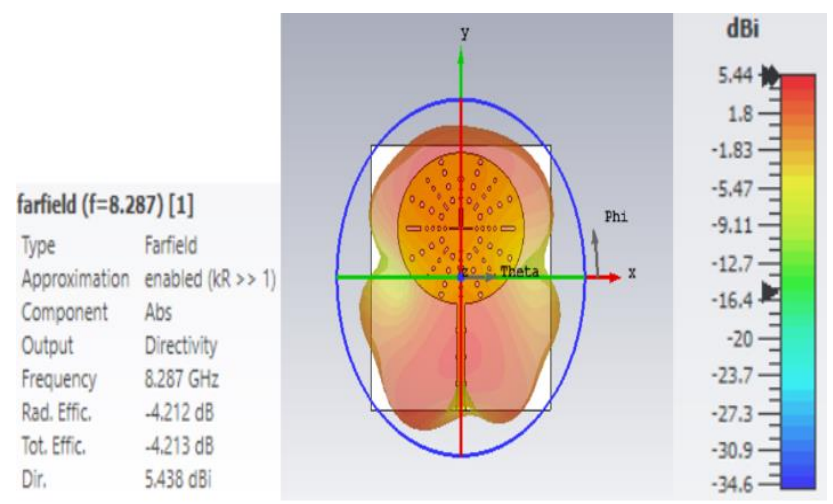

(c)

Figure 10. The $3 \mathrm{D}$ radiation pattern of the adjusted antenna in (a) $f=6.213 \mathrm{GHz}$ (b) $f=7.624 \mathrm{GHz}$ (c) $f=8.287 \mathrm{GHz}$

\section{Conclusions}

An elliptical triple-band microstrip antenna is designed for satellite applications. The antenna has dimensions of $(35 \times 34 \times 1.6) \mathrm{mm}^{3}$. The antenna patch is mounted on a substrate with a relative dielectric constant $\left(\boldsymbol{\varepsilon}_{\boldsymbol{r}}\right)$ of 4.3 and a tangent loss $(\tan \delta)$ of 0.025 . The built antenna covers frequencies of (6.1-6.3) GHz, (7.4-7.8) $\mathrm{GHz}$ and (8-8.4) GHz. The antenna gain ranges from $1.2 \mathrm{dBi}$ to $2.59 \mathrm{dBi}$. The antenna is adjusted by adding steps to the feed line and slots to the patch, which would improve the performance in particular by minimizing distortion (i.e. less group delay), giving it a better match impedance characteristics. We expect to fabricate the antenna and test it practically in the near future.

\section{Acknowledgement}

The authors wish to thank Al-Mustansiriyah University College of Engineering and the Electrical Engineering Department for the support of the research work.

\section{Conflict of interest}

The authors confirm that the publication of this article causes no conflict of interest.

\section{References}

1. R.H. Thaher and N.B. Hassan,(2019) "Design of p-shaped microstrip patch antenna for wireless communication systems," Indonesian Journal of Electrical Engineering and Computer Science. vol. 15, no. 2, pp. 861869, August.

2. M.I. Hussein, A. Hakam, M. Ouda, and R.M. Shubair,(2016) "Compact low-profile planar elliptical antenna for UWB applications," 2016 10th European Conference on Antennas and Propagation, EuCAP 2016. pp. 2-3, June.

3. R. H. Thaher and S. N. Alsaidy, (2015) "New Compact Pentagonal Microstrip Patch Antenna for Wireless Communications Applications," American Journal of Electromagnetics and Applications. vol. 6, no. 3, pp. 53-64, December.

4. R.H. Thaher and N.B. Hassan, (2018) "Proposed P-shaped Microstrip 
Antenna Array for Wireless Communication Applications," Telkomnika. vol. 16, no. 6, pp. 2597-2607, December.

5. K.M.J. Singh and R. Mishra, (2019)“A Circular Microstrip Patch Antenna with Dual Band Notch Characteristics for UWB Applications," 2018 International Conference on Power Energy, Environment and Intelligent Control, PEEIC 2018. pp. 153156, March.

6. M.S. Soliman, M.O. Al-Dwairi, A.Y. Hendi, and Z. Alqadi, (2019) "A compact ultrawideband patch antenna with dual band-notch performance for WiMAX/WLAN services," 2019 IEEE Jordan International Joint Conference on Electrical Engineering and Information Technology, JEEIT 2019 Proceedings. pp. 831-834, May.

7. I.M. Danjuma, M.O. Akinsolu, C.H. See, R.A. Abd-Alhameed, and B. Liu, (2020) "Design and Optimization of a Slotted Monopole Antenna for Ultra-Wide Band Body Centric Imaging Applications," IEEE Journal of Electromagnetics, RF and Microwaves in Medicine and Biology. vol. 4, no. 2, pp. 140147, April.

8. RuihengZhang, X. Xu, and X. Deng, ( 2019) "An Irregular Elliptical Monopole Antenna for Ultra-Wide-Band (UWB) Applications with Dual Notched Bands," 2018 12th International Symposium on Antennas, Propagation and EM Theory, ISAPE 2018 Proceedings. pp. 1-3, February.

9. Z.U. Islam, I. Nadeem, Z. Ahmed, F.K. Lodhi, F.B. Zarrabi, and M. Haneef, (2019)"UWB Microstrip Antenna with U-Shape Slot for WLAN Band-Suppression Application," 2019 International Conference on Communication Technologies (ComTech). no. ComTech, pp. 26-29, June.

10. A. De, B. Roy, A. Bhattacharya, G. V. Bharat, and A.K. Bhattacharjee, (2020)"Compact UWB monopole antenna with WLAN and X-band satellite filtering characteristics," Proceedings of International Conference on Computation, Automation and Knowledge Management, ICCAKM 2020. pp. 344-347, April.

11. A. Das, S. Pahadsingh, and S. Sahu, (2016) “Compact microstrip fed UWB antenna with dual band notch characteristics," International Conference on Communication and Signal Processing, ICCSP 2016. vol. 1, pp. 751-754, November.

12. A. Singh, (2009) "Dual band E-shaped Patch Antenna (ESPA) for ultra wide band applications," APMC 2009 - Asia Pacific Microwave Conference 2009. pp. 2770-2773, January.

13. A. Patel and M.S. Parihar, (2020) "UWB monopole antenna with triple-band notch rejection," 2019 IEEE Conference on Information and Communication Technology, CICT 2019. vol. 5880, pp. 1-4, April.

14. J. Banerjee, A. Karmakar, A. Saha, et al., (2018) "A compact printed UWB monopole antenna with triple band notch characteristics," 2018 3rd International Conference on Microwave and Photonics, ICMAP 2018. vol. 2018-Janua, no. Icmap, pp. 1-2, May.

15. S. Agrawal, A. Yadav, and R.P. Yadav, (2018) "A compact triple band notched UWB antenna: SRR and feed miniaturization," Proceedings of the 2017 International Conference on Wireless Communications, Signal Processing and Networking, WiSPNET 2017. vol. 2018-Janua, pp. 929933, February.

16. S.A. Ali, D. Jhanwar, and D. Mathur, (2017) "Design of a compact triple bandnotch flower-shaped hexagonal microstrip patch antenna," 2016 International Conference on Information Technology, InCITe 2016 - The Next Generation IT 
Summit on the Theme - Internet of Things:

Connect your Worlds. pp. 293-298, February. 